\title{
Considerações sobre eu e o corpo em Lacan
}

\author{
Michele Cukiert \\ Faculdade de Psicologia - UniFMU \\ Léia Priszkulnik \\ Universidade de São Paulo
}

\begin{abstract}
Resumo
O artigo trata da problemática do eu e do corpo em Lacan, articulados a partir de sua releitura do texto freudiano. Aponta como o autor, interrogando-se sobre a gênese do eu, retoma conceitos freudianos fundamentais tais como ego, identificação e narcisismo. Dessa forma, por meio da elaboração do registro do Imaginário e do esquema conceitual proposto pelo estádio do espelho, afirma a importância da imagem do corpo próprio na formação do eu, marcando também o desconhecimento e a alienação como constitutivos do eu. Indica como as noções de eu e de corpo sofrem transformações correlativas às retificações que Lacan opera em sua teoria, articulando-se também ao Simbólico e ao Real. Assim, no interior do campo psicanalítico delimitado pelo autor, o corpo pode ser pensado e estudado a partir de sua concepção dos três registros fundamentais: do ponto de vista do Imaginário, o corpo como imagem, do ponto de vista do Simbólico, o corpo marcado pelo significante, e do ponto de vista do Real, o corpo como sinônimo de gozo. Retoma a novidade freudiana acerca da corporeidade, afirmando que o corpo em Psicanálise não se reduz ao campo da Biologia. Finalmente, discute de que forma a teoria lacaniana possibilita repensar essa problemática a partir da linguagem.
\end{abstract}

Palavras-chave: Psicanálise lacaniana, Corpo, Clínica psicanalítica, Subjetividade, Lacan.

\begin{abstract}
Some considerations about the moi and the body in Lacan

This article covers the issue of the moi and the body in Lacan, based on his re-reading of Freudian texts. It indicates how the author, questioning the constitution of the moi, goes back to Freudian fundamental concepts such as ego, identification and narcissism. In this way, through the elaboration of the Imaginary level and the proposed conceptual scheme of the mirror stage, it assures the importance of the image of the body in the formation of the moi, making also the unknown and the alienation as constituents of the moi. It indicates how the notions of the moi and the body suffer correlative transformations by the rectifications in Lacan's theory, as do the Symbolic and Real. In this way, within the psychoanalytic field established by the author, the body can be considered and studied through his conception of three central categories. From the point of view of the Imaginary: the body as an image; from the Symbolic point of view: the body affected by the significant; and from the point of view of the Real level: the body as a synonym of enjoyment (jouissance). Discusses the Freudian conception of the body, pointing that it is not limited to the Biological field. Presents how the Lacanian theory allows the redefinition of this problem through the speech.
\end{abstract}

Key words: Lacanian psychoanalysis, The body, Psychoanalytic clinic, Subjectivity, Lacan.

$\mathrm{A}$ problemática do eu e do corpo está presente na obra de Lacan desde os primeiros momentos de sua trajetória pela Psicanálise. Por meio da elaboração do registro do Imaginário e do esquema conceitual proposto pelo estádio do espelho, ele afirma a importância da imagem do corpo próprio na formação do eu. A referên- cia ao corpo também está presente de forma recorrente ao longo de sua obra, sofrendo reformulações correlativas às retificações que ele introduz. Entretanto, na esteira de Freud, o corpo ao qual ele se refere não é o corpo biológico. $\mathrm{O}$ corpo para Lacan é o corpo marcado pelo significante e habitado pela libido, corpo erógeno e singular. Corpo de dese- 
jo e, portanto, de gozo, dimensões que certamente contribuem para repensar a problemática do corpo em Psicanálise à luz da nova perspectiva da linguagem.

Lacan inicia-se na filosofia de Hegel e começa, a partir de 1933, "a interrogar-se sobre a gênese do eu, por intermédio de uma reflexão filosófica concernente à consciência de si” (Roudinesco \& Plon, 1998, p.194). Surge a noção de estádio do espelho, trabalho que marca sua entrada no meio psicanalítico internacional.

Baseado na idéia de que o eu se constrói primeiramente a partir do outro, em especial a partir da imagem que lhe é devolvida pelo semelhante, Lacan marca o desconhecimento e a alienação como constitutivos do eu.

As formulações posteriores, sobre o sujeito, a linguagem e o Outro, apontam por sua vez, para um dos pontos fundamentais da teoria lacaniana, qual seja, o da importância do nascimento do sujeito como submetido à linguagem.

Lacan refere-se ao conjunto terminológico Imaginário, Simbólico e Real, que pode ser considerado como uma constante na sua obra, adquirindo, entretanto, ao longo de sua teorização, novas perspectivas e precisões. Nas palavras de Cesarotto e Leite (1993), os registros lacanianos são "descritos por ele [Lacan] como as três dimensões do espaço habitado pelos seres falantes, como é revelado pela experiência analítica" (p.73). Os autores também indicam que a seqüência do ensino lacaniano pode ter como modelo, ao invés de uma referência temporal, a "lógica interna dos desenvolvimentos teóricos, [que] apontaria três etapas" (p.112). A primeira, de 1936 a 1953, delimitaria o registro do Imaginário. A Segunda, de 1953 a 1976, evidenciaria o registro Simbólico. A terceira, de 1976 a 1980, enfatizaria o registro do Real e a "inter-relação desses três registros" (p.112).

Por mais que Lacan articule gradativamente os três registros em sua teoria, passando a concebê-los no quadro de uma tópica, os conceitos de Imaginário, Simbólico e Real são inseparáveis e devem ser pensados formando uma estrutura.

$\mathrm{Na}$ teoria lacaniana, designa-se pelo nome de tópica a trilogia do Simbólico, Imaginário e Real. Todavia, como afirmam Roudinesco e Plon (1998), essa tópica se transforma ao longo do ensino de Lacan, tendo passado por duas organizações sucessivas: "na primeira (1953-1970), o simbólico exerceu a primazia sobre as outras duas instâncias (S.R.I.) e, na segunda (1970-1978), o real é que foi colocado na posição dominante (R.S.I.)" (p.755).

Com relação à questão do corpo, percorrendo a obra de Lacan, verificamos que apesar de não discutir a corporeidade de forma específica, ele se refere de forma intensiva a essa problemática ao longo de seu ensino, articulando-a aos conceitos e formulações que desenvolve.

Assim, no interior do campo psicanalítico delimitado por Lacan, o corpo pode ser pensado a partir de sua concep- ção dos três registros fundamentais. Nessa perspectiva, ele pode ser estudado por meio de três pontos de vista complementares: do ponto de vista do Imaginário, o corpo como imagem, do ponto de vista do Simbólico, o corpo marcado pelo significante, e do ponto de vista do Real, o corpo como sinônimo de gozo.

Pensar o corpo do ponto de vista do Imaginário implica em levar em conta os primeiros momentos da teoria lacaniana e a forma como a imagem do corpo próprio a partir do outro marca a constituição subjetiva e a imagem assumida pelo sujeito.

O corpo do ponto de vista do Simbólico aponta para a relação que se estabelece entre fala-linguagem-corpo. Tendo como referência o texto Função e Campo da Fala e da Linguagem, escrito por Lacan em 1953, e sua concepção do primado da linguagem, ele diz respeito ao corpo marcado pelo simbólico, no qual as diversas partes podem servir de significantes, isto é, ir além de sua função no corpo vivo.

O corpo do ponto de vista do Real seria sinônimo de gozo, definido não como organismo, mas como "pura energia psíquica, da qual o corpo orgânico seria apenas a caixa de ressonância" (Nasio,1993, p. 37).

Vale notar que a introdução original do conceito de gozo, distinto da noção de prazer, define as diferentes relações com a satisfação que um sujeito falante pode experimentar no uso de um objeto desejado, postulando que a questão da satisfação também se inscreve na rede de sistemas simbólicos que dependem da linguagem.

Procurando formular o surgimento do eu, Lacan retoma conceitos freudianos fundamentais tais como ego, identificação e narcisismo. De fato, por meio da elaboração do registro do Imaginário e do esquema conceitual proposto pelo estádio do espelho, Lacan, na esteira de Freud, estabelece uma íntima relação entre o eu e o corpo na constituição do sujeito.

O estádio do espelho tem ligações com as concepções de Henri Wallon (filósofo, neuro-psiquiatra, psicólogo) sobre a importância do espelho para a aquisição da noção de corpo próprio. "Na perspectiva walloniana, a prova do espelho especificava a passagem do especular para o imaginário e, em seguida, do imaginário para o simbólico" (Roudinesco \& Plon, 1998, p.194), numa operação dialética entre a criança e o espelho, entre o eu e o outro. Lacan retoma as concepções de Wallon e, com base na teoria de Freud e em reflexões filosóficas, o espelho passa a ser o semelhante e o estádio do espelho se transforma numa estrutura ontológica do mundo humano.

A tese de uma constituição do sujeito a partir de um outro, através do qual o eu é levado a conhecer o mundo, aponta para a questão da alteridade e, para a Psicanálise, a alteridade na perspectiva de uma determinação inconsciente. Lacan, procurando especificar o inconsciente freudiano 
(a outra cena), introduz o outro, como semelhante, e o Outro como determinação pelo inconsciente. Segundo Lacan (1981/ 1988, p.170), "temos a noção de que, além do outro com $a$ minúsculo do imaginário, devemos admitir a existência de um outro Outro" ( $a$ de autre, em francês).

Como paradigma do Imaginário, o estádio do espelho se refere à forma como a imagem do corpo próprio, a partir do outro, tem um papel fundamental na formação do eu e na imagem assumida pelo sujeito. Lacan (1975/1986) afirma que "o estádio do espelho (...), não é simplesmente um momento de desenvolvimento. Tem também uma função exemplar, porque revela certas relações do sujeito à sua imagem, enquanto Urbild do eu." (p.91).

Situado entre o sexto e o décimo oitavo mês de vida, o estádio do espelho é a expressão cunhada por ele para designar o momento psíquico no qual "a criança antecipa o domínio sobre sua unidade corporal através de uma identificação com a imagem do semelhante e da percepção de sua própria imagem num espelho" (Roudinesco \& Plon,1998, p.194).

Lacan (1975/1986) afirma que a apreensão imaginária da unidade corporal antecede a própria maturação fisiológica e motora do sujeito, pois

o processo da sua maturação fisiológica permite ao sujeito, num dado momento de sua história, integrar efetivamente suas funções motoras, e aceder a um domínio real do seu corpo. Só que é antes desse momento, embora de maneira correlativa, que o sujeito toma consciência do seu corpo como totalidade. É sobre isso que insisto na minha teoria do estádio do espelho - a só vista da forma total do corpo humano dá ao sujeito um domínio imaginário de seu corpo, prematuro em relação ao domínio real (p. 96).

O estádio do espelho permite também especificar o momento original no qual, a partir da imagem corporal, a criança estabelece uma diferença entre o seu corpo e o mundo exterior. Segundo Lacan (1975/1986, p.96), "é aí que a imagem do corpo dá ao sujeito a primeira forma que lhe permite situar o que é e o que não é do eu". Nesse sentido, afirma ainda que o estádio do espelho

é a aventura original através da qual, pela primeira vez, o homem passa pela experiência de que se vê, se reflete e se concebe como outro que não ele mesmo - dimensão essencial do humano, que estrutura toda a sua vida de fantasia.

Lacan aponta a imagem corporal como capaz de um efeito formador. É o reconhecimento primeiro da criança de sua totalidade no espelho e a antecipação imaginária de um corpo unificado, por meio de uma identificação primordial do sujeito com a imagem, que possibilita à criança ultrapassar o momento pré-especular, marcado por uma imagem de corpo fragmentada, constituindo uma subjetividade.

Avançando a partir da idéia freudiana do papel fundamental da identificação na formação do eu (ego freudiano), ele estabelece que é por uma identificação que a criança antecipa imaginariamente a forma total de seu corpo, instalando o primeiro esboço do eu. Nesse sentido, segundo Lacan (1966/1998a), devemos

compreender o estádio do espelho como uma identificação, no sentido pleno que a análise atribui a esse termo, ou seja, a transformação produzida no sujeito quando ele assume uma imagem - cuja predestinação para esse efeito de fase é suficientemente indicada pelo uso, na teoria, do antigo termo imago (p. 97).

Sendo entendido a partir da imagem e da identificação, o registro do Imaginário, conforme a proposição lacaniana, é também o registro do engodo. Chemama (1995) observa que

na relação intersubjetiva, é sempre introduzida alguma coisa fictícia, que é a projeção imaginária de um sobre a tela simples em que o outro se transforma. É esse o registro do eu, com aquilo que comporta de desconhecimento, de alienação, de amor e de agressividade, na relação dual (p.104).

Em termos lacanianos, o narcisismo coloca em cena não apenas as marcas do processo de identificação, mas um jogo de tensões. Lacan (1981/1988) se refere à noção de narcisismo, afirmando que ela deve ser considerada como "a relação imaginária central para a relação inter-humana" e interroga:

O que cristalizou a experiência do analista em torno dessa noção? Foi antes de mais nada sua ambigüidade. É, com efeito, uma relação erótica - toda identificação erótica, toda apreensão do outro pela imagem numa relação de cativação erótica, se faz pela via da relação narcísica - e é também a base da tensão agressiva (p.110).

Assim, o estádio do espelho evidencia a ambigüidade dessa tensão erótica e agressiva que intervém na formação do eu e nas relações, fazendo com que Lacan afirme, no mesmo texto, que "todo equilíbrio puramente imaginário com o outro está sempre condenado por uma instabilidade fundamental" (p.110).

Leite (1999) assinala que, com a teoria do estádio do espelho, ao retirar de Wallon a evidência de que "antes que a coordenação motora seja neurologicamente possível, a criança já se reconhece no espelho", Lacan mostra o lugar do corpo com relação ao psiquismo, demonstrando a antecipação das funções psicológicas em relação às biológicas como fonte de integração da unidade corporal. Como podemos ler diretamente em Lacan (1975/1986), "o sujeito antecipa-se ao acabamento do domínio psicológico, e essa antecipação dá seu estilo a todo exercício posterior do domínio motor efetivo" (p. 96).

Segundo Leite (1999), essa idéia possibilita a Lacan fundamentar de outra maneira a descoberta de que o eu, en- 
quanto corpo próprio, não se reduz ao biológico, já que Lacan, tanto quanto Freud, demonstrou que existe um corpo que não pode ser reduzido ao orgânico e formalizou o chamado corpo erógeno freudiano com o esquema conceitual proposto pelo estádio do espelho.

Em contraposição à noção de estádio da Biologia, assim como à definição estabelecida por Freud do estádio prégenital (oral e anal) e genital - em função da evolução do sujeito e de sua relação com quatro zonas erógenas que se distribuem por quatro regiões do corpo, Lacan (1975/1986) considera o estádio do espelho como um momento lógico na estruturação do sujeito, ou seja, ele "não é simplesmente um momento do desenvolvimento" (p. 91), conferindo a essa noção um estatuto fenomenológico e estrutural.

Vale lembrar que, com relação ao surgimento do eu [ego], Freud (1914/1974) se refere à passagem do auto-erotismo ao narcisismo, situando nessa passagem a necessidade de uma "nova ação psíquica" e afirmando:

Estamos destinados a supor que uma unidade comparável ao ego não pode existir no indivíduo desde o começo; o ego tem de ser desenvolvido. Os instintos auto-eróticos [pulsões auto-eróticas], contudo, ali se encontram desde o início, sendo, portanto, necessário que algo seja adicionado ao auto-erotismo - uma nova ação psíquica - a fim de provocar o narcisismo (p. 93).

Para Lacan, essa ação é a própria antecipação imaginária de um corpo unificado (Gestalt), a identificação primordial do sujeito com a imagem.

$\mathrm{Na}$ esteira de Freud, para Lacan, os conceitos de eu e de corpo, em sua vertente imaginária, estão diretamente relacionados. Aliás, nesse momento da elaboração lacaniana, o corpo, em sua perspectiva imaginária, surge como a própria matriz fundante do sujeito, afirmando a importância da imagem na causalidade psíquica e na passagem ao narcisismo. Entretanto, ao longo de seu ensino, o conceito de eu e de corpo vão mais-além do estádio do espelho, articulando-se também ao Simbólico e ao Real.

Quinet (1994) observa como a conceituação do estádio do espelho sofre transformações correlativas às retificações que Lacan opera em sua teoria. No final dos anos $30 \mathrm{e}$, sobretudo nos anos 40, Lacan faz uma aproximação da Psicanálise com o registro do Imaginário. Nesse primeiro momento podemos dizer que Lacan faz da imagem o centro da causalidade psíquica. Nos anos 50, o estádio do espelho é articulado a partir do registro Simbólico, sendo reformulado com a introdução do grande Outro, ou seja, nas palavras de Quinet,

com o espelho passando a representar o Outro, onde o sujeito admira seu eu enquanto eu ideal como um objeto do desejo do Outro.(...) Segundo a maneira como se apreende o desejo do Outro, o sujeito terá imagens diferentes de seu eu e também da realidade (p.46).
Nesse segundo momento, com a introdução do registro Simbólico (a partir de 1953), Lacan relativiza o estádio do espelho, submetendo-o à ordem simbólica. A alienação na imagem é substituída pela alienação estrutural ao Outro da cadeia significante, que é, na verdade, a primeira operação de causação do sujeito.

Nos anos 60, o estádio do espelho se articula ao registro do Real e introduz o olhar como objeto $a$ no lugar do Outro. Quinet (1994) esclarece:

Na experiência do espelho, olhar é esse objeto que escapa do corpo do Outro materno que observa o sujeito diante do espelho em estado de jubilação. Objeto fugaz e inapreensível, mas cuja presença situa a experiência especular no âmbito do espetáculo dominado pela pulsão escópica (p.47).

Ao formular o estádio do espelho, pensando a gênese do eu em termos de uma identificação, Lacan se contrapõe às concepções da Psicologia do Ego (Ego Psychology) que prevaleciam basicamente nos Estados Unidos. A idéia de que o eu se constrói primeiramente a partir do outro, em especial a partir da imagem que lhe é devolvida pelo semelhante, implica em tirar a consciência de um lugar central, apontando o eu como sede do desconhecimento, já que o espelho aponta para o próprio engodo da imagem.

Na Ego Psychology o eu surge como instância responsável pela consciência e pela adaptação do indivíduo à realidade externa, sadia, disposta sensatamente a cooperar com a tarefa de restabelecer a saúde, com quem o analista deve buscar uma aliança terapêutica na luta contra o sintoma. Em oposição, Lacan (1975/1986), referindo-se ao estádio do espelho e ao processo de constituição do eu pela via não da consciência, mas do inconsciente, especifica:

$\mathrm{Na}$ análise, a partir do momento em que engajamos o sujeito, implicitamente, numa pesquisa da verdade começamos a constituir sua ignorância. Somos nós que criamos essa situação, e, portanto, essa ignorância. Quando dizemos que o eu nada sabe dos desejos do sujeito, é porque a elaboração da experiência no pensamento de Freud no-lo ensina. Essa ignorância não é, pois, uma pura e simples ignorância. É o que é expresso concretamente no processo da Verneinung, e que, no conjunto estático do sujeito, se chama desconhecimento (p. 194).

Sendo conflito na sua essência, o eu é, portanto, dividido. "Indica que conhece que há alguma coisa que não quer reconhecer", nada quer saber que algo da ordem do desejo lhe diz respeito.

Portanto, a perspectiva imaginária traz conseqüências na conceituação do eu. Ela recoloca o fato de que a idéia de um ego racional, consciente, dono de si e agente do seu querer não passa de mera ilusão. Ao mesmo tempo, ela questiona qualquer suposição de unidade do eu: sendo marcado pela 
divisão, ele é absolutamente diverso da noção psicológica de um indivíduo (uno), harmonioso e completo. Assim, Lacan (1981/1988) critica a idéia de um eu racional, opondo-se à idéia "que inspira toda a psicologia clássica, acadêmica, (...) de que os seres humanos são seres adaptados" (p. 99).

Conforme visto, para Lacan, a imagem corporal tem um papel fundamental na constituição do sujeito, já que é a imagem especular que possibilita à criança estabelecer a relação de seu corpo e de seu eu com a realidade que a cerca. Entretanto, o que há de mais essencial na assunção da imagem do corpo no espelho, é que a criança obtém nesse momento a autentificação e o reconhecimento dessa imagem como de um sujeito.

Se há um processo de identificação no campo especular, na medida em que a criança assume determinada imagem de si mesma, ele não se reduz a isso, "pois nunca é com seus próprios olhos que a criança se vê, mas sempre com os olhos da pessoa que a ama ou detesta" (Chemama, 1995, p. 58). Portanto, para se constituir, é preciso que a criança seja objeto do olhar e tenha um lugar no campo do Outro, cujo reconhecimento, na medida em que a nomeia, permite sua entrada no registro Simbólico.

Nesse sentido, é através do outro que a criança aprende a se reconhecer. Isto implica em pensar que seu desejo, tal como seu corpo, não é inicialmente vivido como seu, mas projetado e alienado no outro. A criança inicialmente é o desejo da mãe. Assim, o grande impasse da relação dual imaginária é esse de que não há o reconhecimento de dois desejos, dois sujeitos, mas de um desejo alienado no desejo do outro.

A saída para essa alienação é a entrada do Simbólico, pois é por meio dele que há o advento do sujeito, sujeito do próprio desejo, ali onde antes havia apenas o desejo da mãe. De fato, o Imaginário como registro da identificação especular interpela e surpreende o sujeito a todo o momento, evocando uma articulação com o registro Simbólico.

Para Garcia-Roza (1988), há uma maior precisão se pensarmos o registro Imaginário como um momento subordinado à ordem simbólica, pois, "diante dos três registros a que Lacan se refere - o imaginário, o real e o simbólico -, este último é que deve ser tomado como determinante". Segundo ele:

Quando dizemos que a fase dual que caracteriza o imaginário é anterior ao acesso ao simbólico por parte do 'infans', isso não quer dizer que o simbólico esteja ausente. Apesar de a criança não ter ainda acesso à sua própria fala, ela é falada pelos outros, ela já surge num lugar marcado simbolicamente. Ela mesma não dispõe ainda de uma função simbólica própria, no entanto é, desde o seu nascimento e mesmo antes dele, "simbolizada" pelos outros. O imaginário não é, pois, autônomo em relação ao simbólico, mas um momento subordinado à Ordem Simbólica (p. 213).
A ordem simbólica, portanto, pré-existe ao sujeito. Além de marcar o sujeito, ela permanece, ou seja, segundo Lacan (1981/1988), "subsiste como tal fora do sujeito" (p. 115). Dessa forma, antes do nascimento do corpo biológico e da criança, o Simbólico já está presente no discurso e nas expectativas dos pais e do social. Paradoxalmente, após a morte, para além do corpo biológico, permanece o nome vivificado pelo símbolo.

É importante assinalar que, mesmo enfatizando o aspecto simbólico da linguagem, Lacan (1975/1986) inclui o corpo em seu esquema mental, afirmando que o discurso de que se trata na pesquisa psicanalítica da verdade não se dá somente pelo verbo, mas também pelo corpo. Segundo ele:

Somos pois levados pela descoberta freudiana a escutar no discurso essa palavra que se manifesta através, ou mesmo apesar, do sujeito. Pelo seu corpo mesmo, o sujeito emite uma palavra que é, como tal, palavra da verdade, uma palavra que ele nem mesmo sabe que emite como significante. É que ele diz sempre mais do que quer dizer, sempre mais do que sabe dizer (p. 303).

Nesse mesmo sentido Lacan (1966/1998b) faz referência ao corpo e à materialidade da linguagem, afirmando que

a fala, com efeito, é um dom de linguagem, e a linguagem não é imaterial. É um corpo sutil, mas é corpo. As palavras são tiradas de todas as imagens corporais que cativam o sujeito; podem engravidar a histérica, identificar-se com o objeto do Penis-neid, representar a torrente de urina da ambição uretral, ou o excremento retido do gozo avarento (p. 302).

Assim, as articulações lacanianas possibilitam situar que o corpo, em sua vertente simbólica, é o corpo marcado pelo significante, no qual o inconsciente também se escreve e pode ser decifrado. Como sugere Nasio (1993), o corpo pensado a partir da linguagem é o "corpo falante", e isso significa que

o corpo que interessa à Psicanálise não é um corpo de carne e osso, mas um corpo tomado como um conjunto de elementos significantes. $O$ corpo falante pode ser, por exemplo, um rosto, na medida em que um rosto se compõe de linhas, expressões (...). O adjetivo "falante" não indica que o corpo fale conosco, mas que ele é significante, ou seja, que comporta significantes que falam entre si. (...) Quando um rosto suscita um sentimento, ele é um corpo-imagem; mas, quando o mesmo rosto desperta um dizer imprevisto, ele é um corpo-significante (p.149).

Retomando o estatuto do corpo na teoria lacaniana, Nasio (1993) afirma que ela define o corpo segundo dois parâmetros fundamentais que delimitam o campo psicanalítico: "a fala e o sexo". Essa precisão possibilita estabelecer a distinção entre o corpo da Medicina e o corpo, sexual e gozoso, abordado pela Psicanálise, pois 
contrariamente ao cirurgião, que se coloca diante do corpo de seu doente e o trata como um organismo, sem se preocupar em saber se ele fala ou goza, o psicanalista, por sua vez, deverá constantemente referir-se, direta ou indiretamente, aos parâmetros que são a fala e o sexo, e, assim, conceber dois estatutos do corpo: o corpo falante e o corpo sexual (p. 148).

O corpo falante, como já assinalado, é o corpo marcado pelo Simbólico, ao mesmo tempo, o corpo é sexual, porque "o corpo é todo gozo e porque o gozo é sexual". Ainda seguindo as articulações lacanianas, Nasio aponta o gozo como "o impulso de energia do inconsciente, quando ela é gerada pelos orifícios erógenos do corpo, quando ela se exprime, seja diretamente pela ação, seja indiretamente pela fala e pela fantasia".

Nasio (1993) propõe também que, "do ponto de vista do Real, temos o corpo sinônimo de gozo" (p. 151). As relações entre o corpo e o gozo são repletas de nuances. $\mathrm{O}$ autor reflete sobre o caráter contraditório de que se reveste a definição de gozo na teoria lacaniana, introduzida por volta de 1967, assinalando que Lacan repetiu inúmeras vezes: "só existe gozo do corpo". Quase na mesma época, ele afirmou, ao contrário, "a disjunção entre o corpo e o gozo". Na leitura do autor, "esses ditos lacanianos não são contraditórios, desde que admitamos que a palavra corpo é empregada com uma acepção diferente em cada uma dessas formulações".

A primeira afirmação, segundo Nasio (1993), pode ser interpretada assim: "para que um corpo goze, (...) é preciso que esteja vivo" (p.152). Na segunda formulação, na qual se afirma a disjunção entre corpo e gozo, a palavra corpo se traduz por organismo; assim, "o gozo é (...) radicalmente disjunto do corpo, (...) desde que consideremos esse corpo como o corpo orgânico, aquele de que a Psicanálise não tem de se ocupar"'(p.152).

Segundo Roudinesco e Plon (1998, p. 645), o registro do Real é introduzido por Lacan em 1953, tendo sido extraído "simultaneamente, do vocabulário da Filosofia e do conceito freudiano de realidade psíquica, para designar uma realidade fenomênica que é imanente à representação e impossível de simbolizar". Temos, então, que na categoria do Real, Lacan "colocou a realidade psíquica, isto é, o desejo inconsciente e as fantasias que lhe estão ligadas, bem como um 'resto': uma realidade desejante, inacessível a qualquer pensamento subjetivo".

O Real pode ser pensado como um tempo anterior às palavras, um momento pré-simbólico. De fato, Lacan (1978/ 1985) se refere a um certo "para além da referência interhumana, que é propriamente o para além simbólico" (p.101). Fink (1998) procura especificar o Real nos termos da teoria de Lacan - retomando a afirmação lacaniana de que "a letra mata (...) o real que havia antes da letra, antes das palavras, antes da linguagem" - e articula o Real ao corpo:

O Real é, por exemplo, o corpo de uma criança "antes" do domínio da ordem simbólica, antes de controlar os esfíncteres e aprender os costumes do mundo. No curso da socialização, o corpo é progressivamente escrito ou sobrescrito com significantes; o prazer está localizado em determinadas zonas, enquanto outras são neutralizadas pela palavra e persuadidas a se conformarem com as normas sociais e comportamentais. Levando a idéia de Freud sobre a perversidade polimorfa às últimas conseqüências, é possível ver o corpo de uma criança como apenas uma zona erógena contínua, no qual não haveria zonas privilegiadas, nenhuma área na qual o prazer estivesse circunscrito no início (p. 43).

Mas o Real não deve ser entendido apenas como anterior à letra. Fink (1998) observa que o Real não desaparece por completo quando uma criança assimila a linguagem, esclarecendo que esse registro é melhor compreendido como "aquilo que ainda não foi simbolizado, resta ser simbolizado, ou até resiste à simbolização; pode perfeitamente existir 'lado a lado' e a despeito da considerável habilidade lingüística de um falante" (p. 44).

O Real como substantivo, o impossível de simbolizar, provoca remanejamentos nas concepções lacanianas. Assim, como vimos, o corpo, além de ser afetado pela linguagem, goza. Miller (1998) retoma as afirmações de Lacan de que "é preciso que haja um corpo para gozar, somente um corpo pode gozar" (p. 93), lembrando que a conseqüência dessa evidência é que o corpo não deve ser só pensado como simbolizado, "significantizado e (...) simbolizado quer dizer mortificado" (p. 95). Para gozar, é necessário o corpo vivo.

Assim, amplia-se o lugar do corpo na teoria lacaniana na medida em que ele é repensado à luz do Real e do gozo. Dessa forma, torna-se possível repensar a problemática do corpo na clínica psicanalítica.

Nota-se que para tratar da problemática do eu e do corpo presentes na clínica e na teoria psicanalítica, é necessário levar em consideração o movimento interno que marca a construção teórico-clínica de Lacan e sua releitura do texto freudiano.

Freud (1916-1917/1976) questiona o homem da razão ocidental, afirmando que o ego (eu) não é senhor nem mesmo em sua própria casa. Avançando sobre as articulações freudianas, Lacan enfatiza o desconhecimento e a alienação como constitutivos de uma subjetividade, mostrando a importância do registro do Imaginário no processo de construção do eu.

$\mathrm{Na}$ esteira de Freud, Lacan estabelece uma íntima relação entre o surgimento do eu, o narcisismo e o corpo. Além disso, retomando a especificidade da noção de corpo em Psicanálise, Lacan mostra que desde Freud há algo 
de revolucionário no olhar psicanalítico sobre o corpo, que é absolutamente distinto do olhar da Medicina.

Estabelecendo a fala e a linguagem como fundamentos da prática analítica, a teoria lacaniana aborda a questão do corpo de forma essencialmente analítica e distinta do manejo feito por outros profissionais (médicos, terapeutas corporais, etc.). Assim, o analista toca o corpo e o sintoma por meio da palavra. Ele intervém sobre o inconsciente (estruturado como linguagem) e sobre a história, obtendo efeitos no corpo, pois, quando do atravessamento pela fala, o corpo também é afetado.

Em Psicanálise não se pode prescindir nem do corpo, nem da palavra. Mais que isso, na análise, não há como separar corpo e palavra. Se a palavra tem efeitos sobre o corpo, se corpo e palavra se entrelaçam, daí decorre a própria possibilidade do tratamento psicanalítico e sua eficácia.

Ao mesmo tempo, a Psicanálise - sendo muitas vezes convocada no exato ponto em que a Medicina se depara com seus limites - mostra que o ser humano não se restringe ao corpo biológico, afirmando o inconsciente e a linguagem como constituintes fundamentais. Nesse sentido, podemos considerar que qualquer abordagem, seja médica, farmacológica, corporal, etc., que aborde o sujeito como puro organismo, desconsiderando o campo do inconsciente e do desejo, faz uma leitura parcial do ser humano.

Para além da Biologia e afirmando o aspecto gozoso e falante do corpo, os avanços formulados por Lacan reafirmam a especificidade da leitura psicanalítica sobre a corporalidade.

Sem dúvida, pensar o corpo marcado pela linguagem fundamenta a abordagem dos fenômenos somáticos e do corpo na cena analítica. Além disso, possibilita redimensionar a contribuição e o aspecto indispensável da Psicanálise em campos de ação específicos tais como os Serviços em Hospitais, Ambulatórios, etc e o tratamento de pacientes com doenças refratárias ou queixas psicossomáticas.

\section{Agradecimentos}

O presente trabalho faz parte da Dissertação de Mestrado "Uma contribuição à questão do corpo em Psi- canálise: Freud, Reich e Lacan”, da primeira autora, sob a orientação da segunda, no Programa de Pós-Graduação em Psicologia Clínica do Instituto de Psicologia da USP. As autoras agradecem o apoio da bolsa FAPESP conferida à primeira autora.

\section{Referências}

Cesarotto, O., \& Leite, M. P. de S. (1993). Jacques Lacan, uma biografia intelectual. São Paulo: Iluminuras.

Chemama, R. (1995). Dicionário de Psicanálise. Porto Alegre: Artes Médicas. Fink, B. (1998). O sujeito lacaniano. Rio de Janeiro: Jorge Zahar.

Freud, S. (1974). Sobre o narcisismo: uma introdução. In Edição standard brasileira das obras psicológicas completas de Sigmund Freud (vol. 14, pp. 85-119). Rio de Janeiro: Imago (Texto original publicado em 1914).

Freud, S. (1976). Conferências introdutórias sobre Psicanálise. Parte III. Teoria geral das neuroses. In Edição standard brasileira das obras psicológicas completas de Sigmund Freud (vol. 16, pp.289-539). Rio de Janeiro: Imago. (Texto original publicado em 1916-1917).

Garcia-Roza, L. A. (1988). Freud e o inconsciente. Rio de Janeiro: Zahar.

Lacan, J. (1985). O Seminário Livro 2: o eu na teoria de Freud e na técnica da Psicanálise. Rio de Janeiro: Jorge Zahar. (Texto original publicado em 1978)

Lacan, J. (1986). O Seminário Livro 1: os escritos técnicos de Freud. Rio de Janeiro: Jorge Zahar. (Texto original publicado em 1975)

Lacan, J. (1988). O Seminário Livro 3: as psicoses. Rio de Janeiro: Jorge Zahar. (Texto original publicado em 1981).

Lacan, J. (1998a). O estádio do espelho como formador da função do eu. In: Escritos (pp.96-103). Rio de Janeiro: Jorge Zahar (Texto original publicado em 1966).

Lacan, J. (1998b). Função e campo da fala e da linguagem em Psicanálise. In: Escritos (pp.238-324). Rio de Janeiro: Jorge Zahar (Texto original publicado em 1966).

Leite, M. P. de S. (1999, junho). O lugar do corpo no tratamento analitico: Lacan e o esquema ótico. Trabalho apresentado no Seminário Psicanálise e Linguagem. São Paulo: Pontifícia Universidade Católica.

Miller J-A (1998). O osso de uma análise. In: Revista da Escola Brasileira de Psicanálise-Bahia $\left(\mathrm{n}^{\mathrm{0}}\right.$ especial, $131 \mathrm{pp}$.). Salvador.

Nasio, J.-D. (1993). Cinco lições sobre a teoria de Jacques Lacan. Rio de Janeiro: Jorge Zahar.

Quinet, A. (1994). A imagem rainha ou a boneca barroca. Opção Lacaniana, $11,46-51$.

Roudinesco, E., \& Plon, M. (1998). Dicionário de Psicanálise. Rio de Janeiro: Jorge Zahar.

Michele Cukiert, doutoranda do Programa de Pós-Graduação em Psicologia Clínica do Instituto de Psicologia da USP, é professora da Faculdade de Psicologia da UniFMU, São Paulo.

Léia Priszkulnik, doutora em Psicologia Clínica pela Universidade de São Paulo, é Professora-Doutora do Departamento de Psicologia Clínica do Instituto de Psicologia da USP e docente e orientadora do Programa de Pós-Graduação em Psicologia Clínica do IPUSP.

Endereço para correspondência: Av. Prof. Mello Moraes, 1721 - Bloco F, Cidade Universitária, 05508-900, São Paulo, SP. Tel.: (11)3091-4173. Fax: (11) 3091-4911. E-mail: [MC] michele@usp.br e [LP] leiapris@ajato.com.br. 